\title{
O VIVER DE DEFICIENTES VISUAIS NO CENTRO DE PORTO ALEGRE: TRABALHO AMBULANTE E ESPAÇOS DE SOCIABILIDADE
}

\author{
Magdalena Sophia Ribeiro de Toledo \\ Cornelia Eckert (Orientação)
}

A presente pesquisa insere-se no projeto NAVISUAL, coordenado pela Professora Dra. Cornelia Eckert, e relaciona-se, aqui, ao exercício etnográfico por ela proposto denominado "A Cidade e os seus Riscos: O Viver de Deficientes Visuais no Centro de Porto Alegre", que tem por objetivo desenvolver um estudo narrativo de porto-alegrenses que portam a deficiência visual, buscando cruzar suas formas singulares de interpretar o contexto urbano vivido na ambiência pública e as formas cotidianas de interação social. ${ }^{1}$

O início da pesquisa deu-se em outubro de 2002, através de "caminhadas pela cidade", conceito extraído de De Certeau ${ }^{2}$ pois, através da experiência de caminhanteobservadora no centro da cidade, poderia perceber seus sons, ritmos e cores, inicialmente de forma anônima em meio à paisagem onde se desenrolam as práticas que eu pretendia pesquisar, a saber, o trabalho de vendedores ambulantes desenvolvido por deficientes visuais. Através dele, busquei investigar como eles percebem este viver e atuar no centro, e de que forma desenvolvem sua relação com a paisagem deste trecho da cidade. As ruas privilegiadas para esta observação foram aquelas em que majoritariamente atuam os deficientes visuais vendedores ambulantes do centro de Porto Alegre, como a avenida Otávio Rocha e as ruas Dr. Flores e Andradas. Também ajudaram-me muito as reflexões de

${ }^{1}$ Resumo do projeto "A Cidade e os seus Riscos: O Viver de Deficientes Visuais no Centro de Porto Alegre", de autoria da Professora Dra. Cornelia Eckert para bolsa PIBIC, UFRGS.

${ }^{2}$ CERTEAU, Michel de. A Invenção do Cotidiano. $3^{\mathrm{a}}$ ed. Petrópolis: Vozes, 1998. 
Magnani ${ }^{3}$ sobre caminhadas sistemáticas na cidade, e o conceito de "etnografia de rua" desenvolvido por Cornelia Eckert e Ana Luiza Carvalho da Rocha ${ }^{4}$.

Neste momento da pesquisa, fiz uso de equipamento fotográfico, tendo em vista um registro mais atento do centro da cidade, que passava desde a escolha do ângulo e a percepção da luz nos diferentes horários do dia, até a análise posterior das fotos, que contribuíram para minhas reflexões sobre a ambiência do centro de Porto Alegre. Para estas reflexões sobre o uso da fotografia no exercício de uma etnografia de rua, novamente foram importantes as contribuições trazidas por Cornelia Eckert e Ana Luiza Carvalho da Rocha em seu artigo "Etnografia de Rua: Um Estudo de Antropologia Urbana":

Se a etnografia de rua se apoia no uso de recursos audiovisuais, como câmeras de vídeo ou fotografia, o olhar do antropólogo por vezes assume um lugar de destaque. E se, em muitos momentos, é a situação de interação que irá introduzir o uso do equipamento audiovisual no trabalho de campo, em outros é a câmera de vídeo ou a máquina fotográfica que irá inserir o antropólogo no seu lugar de pesquisa.

A minha experiência se deu mais de acordo com este segundo momento descrito, num exercício de "fotografar para descobrir", nos termos de Milton Guran". Também contribuiu para minhas reflexões sobre fotografia a leitura de Walter Benjamin ${ }^{6}$.

Já na primeira etapa, a leitura e as reflexões sobre outros textos de antropologia urbana estavam presentes. os consultados, além de Michel De Certeau, CorneliaEckert e Ana Luiza Carvalho da Rocha e Magnani, constam Gilberto Velho ${ }^{7}$ e Ruben Oliven $^{8}$.

3 MAGNANI, José Guilherme Cantor. Quando o Campo é a Cidade: Fazendo Antropologia na Metrópole. In: Na Metrópole: textos de antropologia urbana. São Paulo: Editora USP, 1996.

4 ECKERT, Cornelia e ROCHA, Ana Luiza. Etnografia de Rua: Um Estudo de Antropologia Urbana.

5 Curso de Antropologia Visual "Fotografar para Descobrir/Descobrir para Fotografar", ministrado pelo Prof. Dr. Milton Guran (Universidade Gama Filho/RJ), no anfiteatro do ILEA/IFCH/UFRGS, nos dias 15 e 16 de setembro de 2000, promovido pelo BIEV e Navisual (Laboratório de Antropologia Social do PPGAS/IFCH/UFRGS)

6 BENJAMIN, Walter. Pequena história da fotografia. In: KOTHE, Flávio R. (Org.). Walter Benjamin. $2^{\mathrm{a}}$ ed. São Paulo: Ática S. A., 1991. 256 p.

7 VELHO, Gilberto. Individualismo e Cultura: Notas para uma Antropologia da Sociedade Contemporânea. $4^{\mathrm{a}}$ ed. Rio de

Janeiro: Jorge Zahar Editor, 1987. 149 p. Projeto e Metamorfose. Antropologia das Sociedades Complexas. Rio de Janeiro: Zahar, 1994. A Utopia Urbana: Um Estudo de Antropologia Social. Rio de Janeiro: Zahar, 1989. 
No que se refere especificamente ao centro de Porto Alegre, foram de fundamental importância a monografia de Cláudia Turra Magni sobre o comércio ambulante da sorte ${ }^{9} \mathrm{e}$ a dissertação de Celson Gomes sobre músicos que atuam nas ruas de Porto Alegre ${ }^{10}$. Ambos trabalhos contribuíram para minhas reflexões sobre o centro de Porto Alegre, o trabalho ambulante e o trabalho de deficientes visuais, uma vez que os dois apresentavam, entre seus informantes, deficientes visuais.

Em dezembro de 2002, dando início a uma segunda etapa da pesquisa ${ }^{11}$, busquei situar os deficientes visuais num contexto urbano, tendo sempre em mente a arbitrariedade das fronteiras estabelecidas para se definir um grupo. Já na primeira parte de "Individualismo e Cultura", ao falar do estudo de sociedades complexas, Gilberto Velho alerta que "o primeiro e grave risco metodológico é, ao isolar, por motivos de estratégia de pesquisa, segmentos ou grupos da sociedade, passar a encará-los como unidades realmente independentes e autocontidas" 12 .

Em janeiro de 2003, inicio uma terceira etapa da pesquisa, em que os informantes são apresentados. Neste período, tive a oportunidade de entrevistar Josoel, deficiente visual que trabalha como ambulante no centro de Porto Alegre, sobre sua história de vida. ${ }^{13}$

8 OLIVEN, Ruben George. A Antropologia de Grupos Urbanos. Petrópolis: Vozes, 1985. 53 p. 9 MAGNI, Cláudia Turra. O Comércio Ambulante da Sorte. Porto Alegre, 1991, monografia.

10 GOMES, Celson Henrique Souza. Formação e Atuação de Músicos das Ruas de Porto Alegre: Um estudo a partir de relatos de vida. Dissertação (Mestrado em Música). Instituto de Artes, Universidade Federal do Rio Grande do Sul, Porto Alegre.

1 Nesta etapa, conforme dito, foram importantes os trabalhos de Cláudia Magni e Celson Gomes, bem como o de Sandro Rillo (RILLO, Sandro Belloli. A Cidade e os seus riscos: o viver de deficientes visuais em Porto Alegre. Porto Alegre, 2001.), que me antecedeu na pesquisa, o do grupo de alunos orientados pela Professora Anita Brumer na disciplina de "Oficina de Pesquisa 2002", do Departamento de Sociologia da UFRGS (A Oficina de Pesquisa desenvolveu-se durante o primeiro semestre de 2002 (junho a outubro de 2002), sob a responsabilidade da professora Anita Brumer (anita@vortex.ufrgs.br) e com a participação dos alunos: Adenir Antônio Lopes Carvalho, Adriane Corrêa Ramalho, Daniel Gustavo Mocelin, Juliano Orlandi, Katiuci Pavei, Luiz Antônio Pasinato, Pedro Justino Moiano dos Santos, Maria Aparecida M. dos Santos e Nara Regina Dubois de Jesus. Todos são co-autores deste trabalho, intitulado "Caminhos e descaminhos da cidadania: perspectivas da inclusão social, econômica, cultural e política dos portadores de deficiência visual em Porto Alegre") e o de Goffman (GOFFMAN, Erving. Estigma: Notas sobre a Manipulação da Identidade Deteriorada. $4^{\mathrm{a}}$ ed. Rio de Janeiro: Guanabara, 1988.), do qual retirei os conceitos de "estigma" e "carreira moral".

12 VELHO, Gilberto. Individualismo e Cultura: Notas para uma Antropologia da Sociedade Contemporânea. $4^{\text {a }}$ ed. Rio de

Janeiro: Jorge Zahar Editor, 1987. 149 p., p. 15

13 Para estudo de história de vida, recorremos a LANGNESS, L.L. A História de Vida na Ciência Antropológica. São Paulo: E.P.U., 1973. ; QUEIROZ, Maria Isaura. "Relatos orais: do indizível ao dizível" In: Enciclopédia Aberta de Ciências Sociais. São Paulo: 1988. ; VELHO, Gilberto. "Trajetória Individual e Campo de Possibilidades". In: Projeto e Metamosfose: Antropologia das Sociedades Complexas. Rio de Janeiro: Jorge Zahar, 1994. 
Assim, como metodologia de pesquisa utilizei as técnicas de observação participante, notas em diário de campo, caminhadas sistemáticas pelo centro da cidade, fotografia, entrevista (realizada com Josoel e com Altair Paulo, Presidente da ACERGS Associação dos Cegos do Rio Grande do Sul), história de vida (realizada com Josoel) e questionamentos assistemáticos provenientes de "conversas informais", tão importantes ao método etnográfico, que realizo no centro da cidade com outros vendedores ambulantes e na própria associação.

As divisões deste artigo seguem as etapas apresentadas. Assim, desenvolvo, numa primeira parte, "Caminhadas pela Cidade", algumas reflexões sobre etnografia de rua, a partir da minha experiência, buscando desenvolver os marcos teóricos já citados. A segunda parte, "Os Deficientes Visuais no Centro de Porto Alegre", refere-se às reflexões sobre os deficientes visuais no contexto urbano, aqui representado pelo centro de Porto Alegre, finalizando com uma apresentação da ACERGS (Associação dos Cegos do Rio Grande do Sul) e de como os atores envolvidos se relacionam com este espaço. Na terceira parte, sobre história de vida, apresento Josoel, meu principal informante. A quarta e última parte é dedicada às questões éticas e tensões em campo que constatei durante a pesquisa.

\section{Caminhadas pela cidade}

\footnotetext{
(...) A caminhada - pelo efeito de estranhamento que induz - permite treinar e dirigir o olhar por uma realidade inicialmente tida como familiar e conhecida. Para tanto, devia obedecer a um timing que a distinguisse do andar apressado e alheio do usuário habitual, assim como do passeante descomprometido. ${ }^{14}$
}

Esta epígrafe, extraída de artigo de Magnani (1996), expressa exatamente o espírito com o qual iniciei esta pesquisa, utilizando-me das técnicas de caminhadas sistemáticas, observação direta, notas em diário de campo e recursos fotográficos. As caminhadas foram a melhor forma encontrada para ressemantizar o universo do centro de Porto Alegre, por mim já conhecido, absorver seus sons, ritmos, formas e cores, identificar seus personagens, constatar suas rupturas e regularidades. 
Além disso, estas caminhadas anônimas permitiram a observação dos locais de convívio (neste caso, tendo como fio condutor o trabalho) dos sujeitos de minha pesquisa, os deficientes visuais. Conforme apontado por Magni (1991), em sua pesquisa sobre o comércio ambulante da sorte - "Para

(...) reconhecer códigos e espaços de atuação dos vendedores ambulantes de bilhetes da sorte, primeiramente apenas observei de forma anônima." ${ }^{15}$ - também eu encontrei no anonimato inicial uma forma de reconhecimento de alguns códigos e espaços do grupo que pretendia estudar.

A minha área de percurso foi sendo delimitada gradativamente, à medida que observava os pontos de comércio ambulante que mais apresentavam deficientes visuais. Assim, minhas caminhadas sistemáticas aconteceram inicialmente na Av. Otávio Rocha, no trecho entre as esquinas das ruas Mal. Floriano Peixoto e Dr. Flores:

Chego à Otávio Rocha na metade da manhã, mas o sol já está muito forte para fotografar. Decido, então, perceber o seu movimento, seus prédios antigos, suas calçadas da direita e da esquerda apinhadas de pedestres apressados que descem para a rua para desviar de alguém disputando, às vezes, espaço com os táxi- lotação que recentemente passaram a circular por ali. É evidente que circular por essas ruas apinhadas, identificadas, pela maioria das pessoas, como lugar de comércio ou passagem, influencia o caminhar. Também eu acabo caminhando mais rápido, para não atrapalhar as pessoas ou não ser "atropelada" por elas e, por isso, faço umas três idas e vindas pelas quadras que vão da Rua Dr. Flores à Marechal Floriano. Tudo ali parece aguçar os sentidos. O barulho, as cores, o movimento. Lojas, na sua maioria, de roupas e de material fotográfico, cujas sobrelojas permitem perceber prédios antigos lindos mas mal conservados, como um resquício de um centro glamouroso, de outra época, disputam o espaço da calçada com os vendedores ambulantes, divididos basicamente em vendedores de óculos de sol e de bilhetes lotéricos, estes últimos, deficientes visuais, além de moças vestidas com uma capa amarela com os dizeres "Compro Ouro" e de panfleteiros distribuindo propaganda de alguns tipos de comércio realizados nos prédios da rua, como restaurantes e uma Academia de Ginástica. (Trecho de diário de campo, 14 de novembro de 2002)

14 MAGNANI, José Guilherme Cantor. Quando o Campo é a Cidade: Fazendo Antropologia na Metrópole. In: Na Metrópole: textos de antropologia urbana. São Paulo: Editora USP, 1996. p.36, grifo do autor.

15 MAGNI, Cláudia Turra. O Comércio Ambulante da Sorte. Porto Alegre, 1991, monografia, p.1. 
Este trecho demonstra que a busca do timing descrito por Magnani (1996) no caminhar na cidade nem sempre é fácil quando o local da caminhada é o centro. Apesar de tentar esta espécie de "meio termo" para o caminhar, muitas vezes o ritmo apressado dos transeuntes do centro determinavam meus próprios passos. Neste momento, foi fundamental o uso da fotografia, em que o parar para fotografar representava uma tentativa de olhar mais atento para o registro do instante, um momento para (re)ajustar o foco, o enquadramento e, novamente impregnada de um olhar mais sistemático e atento, retomar o timing. Chegara, pois, o momento descrito por ECKERT e ROCHA ${ }^{16}$ :

No decorrer desta experiência etnográfica na rua, no bairro, na cidade, a introdução de instrumentos audiovisuais como a câmera fotográfica e/ou a câmera de vídeo, passam a fazer parte do seu olhar e atitude de coleta de dados de pesquisa: o exercício de etnografia de rua, inclui então, "a câmera na mão".

Mas não é somente este movimento frenético descrito que caracteriza a Av. Otávio Rocha nos dias de semana. Esta avenida é cortada por um canteiro que divide suas calçadas e, neste, o "tempo" que parece operar é outro:

\footnotetext{
Mas não é só desta "loucura" que é formada a Otávio Rocha. Na parte central da rua, numa espécie de canteiro com alguns bancos de praça, árvores, orelhões, uma banca de revista e uma grande tenda de floristas, descansam ou conversam idosos, menores e moradores de rua. Este canteiro, assim, forma uma área de descanso que contrasta com o ritmo frenético e barulhento das outras duas mãos da rua, como a formar uma espécie de oásis no deserto - ainda mais com o calor e o sol escaldante que fazia - com outro tempo, um tempo de outra época, onde se senta no bancos de praça, se conversa em pequenos grupos, compra-se flores e revistas. Até o comércio desta pequena faixa central, intermediária, quase obscurecida em meio ao movimento dos transeuntes, parece ter parado no tempo. As lojas da moda e os ambulantes dos "objetos da moda" atualmente, os óculos de sol coloridos - ficam do lado de fora, gritando entre os pedestres apressados e as lotações. No centro, as floristas oferecem - "Rosa, moça?" - como pregões deslocados no tempo. (Trecho de diário de campo, 14 de novembro de 2002)
}

16 ECKERT, Cornelia e ROCHA, Ana Luiza Carvalho da. Etnografia de Rua: Um Estudo de Antropologia Urbana. 
Esta "supressão do tempo", aliás, parece operar nas relações que os deficientes visuais, enquanto ambulantes, desenvolvem com o centro. À medida em que trabalham em pontos específicos do centro da cidade (questão que será melhor desenvolvida na próxima parte), não é raro encontrá-los "batendo um papo" em esquinas e horários prédeterminados, numa espécie também de subversão do espaço revelada por suas "táticas e práticas" (De Certeau: 1998) cotidianas de sobrevivência. Esta subversão do espaço é assim descrita por Herbert de Souza:

\footnotetext{
Ultrapassando em muito as funções clássicas de passeio e circulação, elas [as ruas] cumprem funções outras e viram casas, depósitos de lixo, locais de comércio e, finalmente, último local de sobrevivência ou morte daqueles que o sistema se encarregou de excluir. Os planejadores urbanos projetam suas funções, e a realidade social se encarrega de ocupá-las com disfunções. 17
}

Por fim, acabei por expandir meu trajeto, nele incluindo a Rua dos Andradas (tradicionalmente conhecida como Rua da Praia), da rua Dr. Flores até a esquina dessa com a Av. Borges de Medeiros (conhecida como Esquina Democrática). A Rua da Praia também é um local repleto de vendedores ambulantes, cujas atividades são facilitadas pelo fato de nela, no trecho pesquisado, não transitarem carros. O fluxo de pedestres é intenso, bem como o apelo visual: bancas de revista, círculos de pessoas conversando (em geral, homens idosos, mais uma vez podendo ser analisados sob a ótica da supressão do tempo e subversão do espaço), lixeiras, postes e orelhões (identificados pelos deficientes visuais como um dos obstáculos enfrentados em suas caminhadas pelo centro) no espaço central da rua e, nos dois lados, lojas diversas instaladas, em geral, no andar térreo de prédios antigos, músicos e outros artistas de rua (estes últimos, geralmente, formando círculos ao seu redor) e, é claro, pedestres e vendedores ambulantes nos dois sentidos. Estes vendem os mais variados produtos, bilhetes lotéricos, giz para matar formigas e baratas (atualmente, produto vendido predominantemente pelos deficientes visuais), óculos de sol, brinquedos, 
carteirinhas de clubes de futebol, dentre outros, fora aqueles que distribuem panfletos de propaganda de restaurantes, academias de ginástica, sistemas de crédito, cursos de computação, cursos de línguas, locais de revendas de lingerie, cabeleireiros, mães de santo, enfim, todo tipo de produto ou serviço. São práticas que revelam táticas, estratégias de apropriação do espaço:

Muitas práticas cotidianas (falar, ler, circular, fazer compras ou preparar as refeições, etc.) são do tipo tática. E também, de modo mais geral, uma grande parte das 'maneiras de fazer': vitórias do 'fraco' sobre o mais 'forte' (os poderosos, a doença, a violência das coisas ou de uma ordem, etc.), pequenos sucessos, artes de dar golpes, astúcias de 'caçadores', mobilidades da mão-de-obra, simulações polimorfas, achados que provocam euforia, tanto poéticos quanto bélicos. Essas performances operacionais dependem de saberes muito antigos. (...) Em nossas sociedades, elas se multiplicam com o esfarelamento das estabilidades locais como se, não estando mais fixadas por uma comunidade circunscrita, saíssem de órbita e se tornassem errantes, e assimilassem os consumidores a imigrantes em um sistema demasiadamente vasto para ser o deles e com a malhas demasiadamente apertadas para que pudessem escapar-lhe. ${ }^{18}$

Assim, chego ao momento de situar os sujeitos da minha pesquisa neste contexto urbano. A trajetória destes sujeitos é aqui recortada e suas vidas, assim, aparecem como um significante sempre em aberto, uma vez que "sem dúvida, na etnografia de rua o perfil de uma comunidade, indivíduo e/ou grupo se configura aos poucos, pois o etnógrafo trabalha pacientemente a partir de colagens de seus fragmentos de interação" ${ }^{\prime 19}$.

\section{Os deficientes visuais no centro de Porto Alegre ${ }^{20}$}

Descrever a cidade, sob um tal ponto de vista, é conhecê-la como locus de interações sociais e trajetórias singulares de grupos e/ou indivíduos cujas rotinas estão referidas a uma tradição cultural que as transcende. Conhecer uma cidade é,

17 SOUZA, 1993, p.11 apud GOMES, Celson Henrique Souza. Formação e Atuação de Músicos das Ruas de Porto Alegre: Um estudo a partir de relatos de vida. Dissertação (Mestrado em Música). Instituto de Artes, Universidade Federal do Rio Grande do Sul, Porto Alegre. p.144.

18 CERTEAU, Michel de. A Invenção do Cotidiano. $3^{\mathrm{a}}$ ed. Petrópolis: Vozes, 1998. p.47, grifos meus.

19 ECKERT, Cornelia e ROCHA, Ana Luiza Carvalho da. Etnografia de Rua: Um Estudo de Antropologia Urbana.

20 Os deficientes visuais aos quais estou me referindo neste capítulo, bem como ao longo do trabalho, são os deficientes visuais de classes populares. 
assim, não só apropriar-se de parte de um conhecimento do mundo, ou seja, os saberes e fazeres dos habitantes e o que conheço desta experiência de pesquisa junto a eles, quanto desvendar o conhecimento na busca de situar meu próprio se em relação ao ser do Outro na cidade. ${ }^{21}$

\section{O deficiente visual numa sociedade complexa: possíveis significados a partir da observação de seu cotidiano no centro de Porto Alegre}

O primeiro cuidado que se deve ter ao estudar grupos urbanos, alerta Gilberto Velho $^{22}$ é, ao isolá-los por motivos de estratégia de pesquisa, não tratá-los como "unidades realmente independentes e autocontidas" ${ }^{\text {"23 }}$. Magnani (1996) alerta para o mesmo risco, o qual chama de "tentação da aldeia". Assim, ao tratar os deficientes visuais que trabalham como ambulantes no centro de Porto Alegre como um grupo, não os tratarei enquanto grupo isolado, mas em profunda e constante relação com a dinâmica das sociedades complexas. O próprio trabalho de ambulante, na maioria dos casos, explicita a relação direta com a realidade do trabalho informal no Brasil.

Sobre a noção de complexidade, Gilberto Velho traz "a idéia de uma heterogeneidade cultural que deve ser entendida como a coexistência, harmoniosa ou não, de uma pluralidade de tradições cujas bases podem ser ocupacionais, étnicas, religiosas, etc." ${ }^{24}$. Sem negar que a divisão social do trabalho e a heterogeneidade cultural possuam uma relação, Gilberto Velho nos diz, ainda, que "é questão importante a verificar quando e como as diferentes tradições culturais de uma sociedade complexa podem ou devem ter como explicação a divisão social do trabalho"25.

A partir destas questões levantadas, realizei algumas reflexões sobre os deficientes visuais que trabalham como ambulantes no centro, especialmente no tocante à questão específica das diferenças de tradições culturais em sua relação com a divisão social do trabalho. Em que medida, para o deficiente visual, a identidade de cego não vem

21 ECKERT, Cornelia e ROCHA, Ana Luiza. Etnografia de Rua: Um Estudo de Antropologia Urbana.

22 VELHO, Gilberto. Individualismo e Cultura: Notas para uma Antropologia da Sociedade Contemporânea. $4^{\mathrm{a}}$ ed. Rio de Janeiro: Jorge Zahar Editor, 1987. 149 p.

23 Op.cit., p.15. 
primeiro, especialmente entre aqueles de nascença que, através de um forte processo de socialização (o Instituto Santa Luzia ${ }^{26}$ constitui um exemplo) aprendem, primeiro, a ser cegos, viver, se relacionar e se perceber enquanto cegos? Minha hipótese é a de que, no caso dos deficientes visuais (ao menos os de nascença), uma vez que eles formam um grupo, com um compartilhamento de símbolos próprios, códigos específicos, etc. perpassado por um estigma (nos termos de Goffman ${ }^{27}$ ) a identidade de cego vem antes e predomina sobre a oferecida, posteriormente, pela divisão social do trabalho. Mas, mais do que isso, no caso dos deficientes visuais ambulantes, ela não apenas vem antes e predomina como, quando não a determina, substantivando a identidade de ambulante (o cego ambulante) a marca profundamente, adjetivando-a (o ambulante cego). Esta hipótese é apoiada pelo conceito de Erving Goffman de "carreira moral":

As pessoas que têm um estigma particular tendem a ter experiências semelhantes de aprendizagem relativa à sua condição e a sofrer mudanças semelhantes na concepção do eu - uma "carreira moral" semelhante, que é não só causa como efeito do compromisso com uma sequiência semelhante de ajustamentos pessoais. (...) Uma das fases desse processo de socialização é aquela na qual a pessoa estigmatizada aprende e incorpora o ponto de vista dos normais, adquirindo, portanto, as crenças da sociedade mais ampla em relação à identidade e uma idéia geral do que significa possuir um estigma particular. Uma outra fase é aquela na qual ela aprende que possui um estigma particular e, dessa vez detalhadamente, as consequiências de possuílo. 28

\section{O deficiente visual trabalhador ambulante do centro de Porto Alegre}

Magni (1991), em sua pesquisa sobre o comércio ambulante da sorte, identifica duas categorias de ambulantes presentes no centro de Porto Alegre: "a dos subempregados, constituída pelos deficientes físicos e idosos, que dedicam-se a esta atividade

\footnotetext{
24 Op.cit., p.16.

25 Idem.

26 Escola profissionalizante para pessoas portadoras de deficiência visual, preferencialmente.

27 GOFFMAN, Erving. Estigma: Notas sobre a Manipulação da Identidade Deteriorada. $4^{\mathrm{a}}$ ed. Rio de Janeiro: Guanabara, 1988.
} 
tradicionalmente, e a dos desempregados, que, nesta condição recentemente vêm invadindo este mercado de trabalho (...)" ${ }^{\prime 29}$. De fato, durante minhas caminhadas pela cidade, pude perceber o comércio ambulante como uma atividade realizada por muitos deficiente visuais, embora não se possa dizer, quase doze anos após a realização desse trabalho, que de forma predominante:

Mais uma vez chego pelo Mercado Público até a Otávio Rocha, onde encontro os três deficientes visuais que lá trabalham vendendo bilhetes lotéricos nos mesmos lugares, na calçada de quem chega do Mercado à direita, em seqüência, num trecho de apenas uma quadra, da esquina da Vigário José Inácio até a esquina com a Dr. Flores. Encontram-se sob marquises de outros estabelecimentos comerciais, ao contrário dos vendedores de óculos de sol, não deficientes visuais, que anunciam seus produtos no meio da rua mesmo, só subindo na calçada quando passa alguma lotação. $\mathrm{O}$ movimento de pedestres é incessante. Dobrando à direita na Dr. Flores, e seguindo até sua esquina com a Rua da Praia, encontro um outro senhor deficiente visual, sentado, vendendo giz para matar baratas num tabuleiro. Sigo pela Rua da Praia, e lá o comércio ambulante parece ter mais vendedores que não são deficientes, à exceção da Esquina Democrática, onde encontro outro deficiente visual vendendo bilhetes lotéricos em frente a uma loja de roupas.

(Trecho de diário de campo, 8 de novembro de 2002)

Entretanto, conforme identificado, ainda há locais do centro que podem ser identificados como pontos em que se encontram, predominantemente, deficientes visuais. Estes lugares podem ser chamados, nos termos de Magnani (1996), de "pedaços":

Ruas, praças, edificações, viadutos, esquinas e outros equipamentos estão lá, com seus usos e sentidos habituais. De repente, tornam-se outra coisa: a rua vira trajeto devoto em dia de procissão; a praça transforma-se em local de compra e venda; o viaduto é usado como local de passeio a pé; a esquina recebe despachos e ebós, e assim por diante. Na realidade são as práticas sociais que dão significado ou ressignificam tais espaços. (...) Quando, porém, algumas das práticas sociais que estão na base desses sistemas de classificação tornam-se recorrentes, com usos mais regulares e

28 Op.cit., p.41.

29 MAGNI, Cláudia Turra. O Comércio Ambulante da Sorte. Porto Alegre, 1991, monografia, p.4, grifos meus. 
reconhecíveis, permitem estabelecer novos recortes e trabalhar com outras categorias. (...) Não é difícil reconhecer a existência de pedaços também em regiões centrais da cidade (...). ${ }^{30}$

Assim, pode-se identificar a existência, no centro, de "pedaços" que são dos deficientes visuais, os seus "pontos". Estes "pedaços" podem ser de trabalho, como no caso analisado, mas também de lazer, como bares e restaurantes específicos freqüentados por deficientes visuais:

De volta à Otávio Rocha, lá pela $1 \mathrm{~h}$ da tarde, encontro, quase em frente ao Café Haiti, 3 deficientes conversando alegremente (dois homens e uma mulher), o que me fez perceber ue lá é um ponto de encontro. (Trecho de diário de campo de 23 de outubro de 2002, numa das primeiras saídas a campo.)

Dentre estes, a partir das minhas caminhadas e observações, posso citar a Av. Otávio Rocha, no trecho entre as esquinas das ruas Mal. Floriano Peixoto e Dr. Flores e a Rua dos Andradas (Rua da Praia) no trecho que vai da esquina com a Rua Dr. Flores até a esquina com a Av. Borges de Medeiros (Esquina Democrática), trechos que eu já tinha citado no capítulo anterior como os privilegiados para minhas caminhadas sistemáticas. Todos estes "pedaços" demonstram o desenvolvimento de laços de afetividade destes deficientes visuais ambulantes com a própria espacialidade do centro, como já identificado por Rillo ${ }^{31}$ : centro?

Pesquisador: E essa amizade de vocês, deficientes visuais, aqui no

W: Exato nós temos um grupo que se reúne para tomar um cafezinho, sentar, conversar sobre política, futebol e brincadeiras. Porque geralmente o deficiente tem uma particularidade, ele é muito bem humorado, sabe. Então a gente tá sempre brincando.

P: Isso faz com que no final da tarde vocês sempre se juntem?

W: Exato. Cinco horas é sagrado a gente sempre se reúne para tomar um cafezinho ali no bar da esquina. O bar do Baldarate, ali é sagrado. Vamos ali todos os dias.

P: O centro aqui de Porto Alegre, o que você acha?

$\mathrm{W}$ : Eu particularmente gosto muito daqui do centro. Não tenho dificuldade. Eu acho uma cidade muito bonita, e gosto muito aqui do centro.

30 MAGNANI, José Guilherme Cantor. Quando o Campo é a Cidade: Fazendo Antropologia na Metrópole. In: Na Metrópole: textos de antropologia urbana. São Paulo: Editora USP, 1996. Pp. 38, 39. Grifos meus. 
Wilson Borba, 39 anos, deficiente visual vendedor de bilhetes lotéricos esquina democrática. (Trecho de entrevista realizada por RILLO: 2001, p.10)

Mas estes "pontos" específicos, estes "pedaços", na verdade, fazem parte de uma "mancha", a saber, o ciclo do comércio ambulante do centro de Porto Alegre:

Existe uma outra forma de apropriação do espaço quando se trata de lugares que funcionam como ponto de referência para um número mais diversificado de frequientadores. Sua base física é mais ampla, permitindo a circulação de gente oriunda de várias procedências. São as manchas, áreas contíguas do espaço urbano dotadas de equipamentos que marcam seus limites e viabilizam - cada qual com sua especificidade, competindo ou complementando uma atividade ou prática dominante. 32

No caso da "mancha" do comércio ambulante de Porto Alegre, Magni (1991) identifica, em sua pesquisa, um clima de disputa entre os ambulantes deficientes físicos e os que não são portadores de deficiência, como se estes primeiros sentissem o seu "pedaço" ameaçado. Além desta tensão, há ainda uma tensão inerente às oscilações do mercado ambulante, que implica na necessidade do trabalhador ambulante em estar atento às "novidades de mercado" que proporcionem melhores vendas. Em uma entrevista realizada com Josoel $^{33}$, pode-se constatar este movimento:

E a loteria caiu... mais!... Estrondosamente a queda da loteria, sabe? Não se vende mais loto, não se vende mais sena, não se vende mais megasena... Como se vendia antes, não. E daí, então... Que que eu fiz? Apelei pra música, começamos a tocá, começamos a tocar na rua... (...)E agora, de uns tempos pra cá também a música começou a ficar difícil, né? Eu toco ali na Rua da Praia nos dias de semana. Então eu peguei uns giz pra matá barata pra vendê. (...) $\mathrm{O}$ giz é uma febre, né, "essa menina"... Como tudo na vida da pessoa que tá na rua tem fases, né? A fase que mais durou foi a loteria. Mas... O resto é tudo febre, né? É uma febre que dá.

A fala de Josoel exemplifica, ainda, uma constatação feita por Gomes ${ }^{34}$, em sua pesquisa sobre a atuação dos músicos nas ruas de Porto Alegre, que demonstra a música

31 RILLO, Sandro Belloli. A Cidade e os Seus Riscos: O Viver de Deficientes Visuais em Porto Alegre. Porto Alegre, 2001.

32 MAGNANI, José Guilherme Cantor. Quando o Campo é a Cidade: Fazendo Antropologia na Metrópole. In: Na Metrópole: textos de antropologia urbana. São Paulo: Editora USP, 1996, p.40. Grifos do autor.

33 Entrevista realizada em 31 de janeiro de 2003, na sede da ACERGS (Associação dos Cegos do Rio Grande do Sul) 
como mais uma atividade exercida por deficientes visuais que se encontram trabalhando nas ruas.

\section{Mais um "pedaço": a ACERGS}

A ACERGS, Associação dos Cegos do Rio Grande do Sul, cuja sede situa-se no $16^{\circ}$ andar da Galeria do Rosário, no centro da cidade, foi fundada em 20 de outubro de 1967 por um grupo de deficientes visuais ex-alunos do Instituto Santa Luzia. Entrevistei, em 27 de fevereiro de 2003, seu atual presidente, Altair Paulo, e ele falou que a entidade tem por finalidade prestar um serviço de assistência social para os deficientes visuais que passam por necessidades, distribuindo cestas básicas, consultas a oftalmologistas, dentistas, psicólogos e psiquiatras (principalmente para aqueles que perdem a visão depois de adultos), cadastrando-os para a obtenção de passe livre nos ônibus e buscando capacitá-los e qualificá-los para a obtenção de empregos. Esta "integração do portador de deficiência visual através do trabalho", nas suas palavras, agora encontra-se sob responsabilidade do SINE (Sistema Nacional de Empregos), embora a ACERGS ainda se preocupe com a questão da qualificação e da capacitação. Este serviço de assistência social é mantido através de apoio de ONGs e pessoas que decidem, individualmente, ajudar. Além disso, Altair relatou que a Associação possui vários departamentos: departamentos de esportes, cultural, audioteca e um departamento de tradições gaúchas, que será fundado oficialmente em março, com cursos de danças tradicionalistas ministrados por deficientes visuais.

Uma das maiores dificuldades relatadas por Altair foram as dificuldades de obtenção de empregos:

Se já está complicado para todo mundo, para nós ainda mais. As pessoas não acreditam no potencial dos portadores de deficiência. A exigência para o cego é maior ainda. A gente tem que provar. É uma luta constante, uma batalha em que a gente tem que "abrir portas a soco".

34 GOMES, Celson Henrique Souza. Formação e Atuação de Músicos das Ruas de Porto Alegre: Um estudo a partir de relatos de vida. Dissertação (Mestrado em Música). Instituto de Artes, Universidade Federal do Rio Grande do Sul, Porto Alegre. 
O olhar que eu dirigi para a ACERGS, entretanto, foi um olhar mais para o significado daquele espaço. Nas três visitas que eu havia feito à Associação no período da tarde (turno de maior movimento, fato que constatei em duas idas no turno da manhã), logo em minha chegada, encontrei, na ante-sala, um grupo de aproximadamente cinco a seis pessoas conversando, rindo, fazendo brincadeiras. O fluxo nesta ante-sala é intenso. Às vezes, o grupo fica maior; outras, os que chegam formam outros pequenos grupos, às vezes até na porta, que fica aberta. Todos parecem se conhecer, e reconhecem-se pelas vozes.

Percebi, portanto, que a maioria deles vai lá mesmo quando não está precisando solicitar algum benefício. Vai lá pelo “bate-papo". Vai lá porque se sente bem. "Eu venho aqui todas as tardes." - disse-me uma das senhoras, certa vez. Ou, como disse Altair durante a entrevista, "alguns vêm em busca de ajuda; outros, vêm em busca de outras pessoas".

Pode-se dizer, assim, que a ACERGS funciona como mais um "pedaço"35, dos deficientes visuais no centro da cidade, dentro do trajeto ${ }^{36}$ descrito. Ela localiza-se exatamente no trajeto onde se podem encontrar as manchas de comércio ambulante das quais os deficientes visuais fazem parte e estabelecem seus outros "pedaços". Uma das entradas da Galeria do Rosário fica justamente na Av. Otávio Rocha. Não por acaso, a primeira deficiente visual com quem estabeleci contato no centro da cidade, conduziu-me até lá por esta entrada:

\begin{abstract}
Conheci dona Júlia ${ }^{37}$ na primeira vez em que falei com um deficiente visual no centro de Porto Alegre sobre a pesquisa. Ela também é deficiente visual e estava conversando, na Otávio Rocha, com o vendedor ambulante que primeiro abordei. (...) Ela mostrou-se extremamente solícita e fez questão de me levar até lá. No caminho, disse-me que é associada há 30 anos, desde os 14 anos, e que é cega de nascença. Pergunto-lhe se ela trabalha como ambulante no centro e ela me diz que trabalha como ambulante, mas "nos bairros". Dona Júlia (...) usa bengala, embora o caminho até a ACERGS ela conheça como ninguém. Foi ela, de fato, quem me conduziu até lá. Foi andando rapidamente, com muita destreza e segurança, praticamente sem encostar sua bengala no chão. Logo entramos na Galeria do Rosário, por uma entrada que eu não conhecia, na própria Otávio Rocha. (Trecho de diário de campo, 14 de janeiro de 2003.)
\end{abstract}

\footnotetext{
35 Conceito extraído de Magnani (MAGNANI, José Guilherme Cantor. Quando o Campo é a Cidade: Fazendo

Antropologia na Metrópole. In: _____ Na Metrópole: textos de antropologia urbana. São Paulo: Editora USP, 1996.) 36 "É a noção de trajeto que abre o pedaço para fora, para o espaço e o âmbito do público." (MAGNANI: 1996, p.45)
} 
Assim, a forma de apropriação do espaço que estes atores realizam na ACERGS permite, ao observador, fazer a leitura de símbolos, fronteiras, identificar valores e diferentes formas de interação. Constitui, na expressão de Magnani (1996), uma "chave para leitura". Através destes atores, estes "pedaços" por eles apropriados funcionam como suportes de cultura e, assim, fazem parte do patrimônio da cidade, configuram aquele repertório de significantes que possibilitam guardar histórias e personagens que estariam esquecidas não fosse pela permanência, na paisagem urbana, de tais suportes. ${ }^{38}$

\section{Josoel}

Josoel foi o deficiente visual com quem tive maior interação nesta experiência etnográfica. Conhecemo-nos na sede da ACERGS, e lá realizei com ele uma primeira entrevista aberta, em 31 de janeiro de 2003. A escolha da sede como lugar da entrevista deveu-se ao fato de lá ela poder ser gravada, pois o barulho do centro da cidade, seu local de trabalho, dificultaria a gravação. Tendo como ponto de partida esta entrevista, venho realizando com Josoel um estudo de história de vida. A técnica de história de vida é assim definida por Queiroz (1988):

O relato de um narrador sobre sua existência através do tempo, tentando reconstituir os acontecimentos que vivenciou e transmitir a experiência que adquiriu. Narrativa linear e individual dos acontecimentos que nele considera significativos. Através dela se delineiam as relações com os membros de seu grupo, de sua profissão, de sua camada social, de sua sociedade global que cabe ao pesquisador desvendar. 39

Josoel é natural de Caçador, Santa Catarina. Desde criança, possui grande interesse por música:

37 Nome fictício.

38 MAGNANI, José Guilherme Cantor. Quando o Campo é a Cidade: Fazendo Antropologia na Metrópole. In: Na Metrópole: textos de antropologia urbana. São Paulo: Editora USP, 1996. p.45.

39 QUEIROZ, Maria Isaura. "Relatos orais: do indizível ao dizível". In: VON SIMSON, Olga de Moraes (Org.).

Experimentos com Histórias de Vida (Itália-Brasil). São Paulo: Vértice, 1988, p.20. 
Pesquisadora: E o senhor aprendeu há muito tempo a música?

Josoel: Desde quatro anos. Eu aprendi sozinho.

P.: Sozinho?

J.: É. Eu tocava gaitinha de boca... É que eu criei uma rádio pra mim.

P.: Como assim?

J.: Eu imaginei uma rádio. Eu fiz assim: fazia as propagandas de rádio, tocava as músicas com a gaitinha... Então eu peguei um pandeirinho, a gaitinha e uma lata de fermento Royal com feijão dentro. Então eu batia com a lata de fermento Rayal no pandeiro pra ter o barulho do pandeiro e do chocalho, né? (...)E... Pra tê a ilusão de que tu tá tocando com um conjunto melódico. E tocava músicas, assim, na gaitinha de boca: "Madureira chorou”,

"Vou visitar a Nália”, tocava músicas assim. E depois, com seis anos eu ganhei a primeira gaitinha de botão. Aí até meu pai queria botar no lixo a gaitinha e eu disse "Não, deixa que eu vou aprender." Em dezesseis dias eu já tava tocando "O Boi Barroso”. Depois, eu fui ganhando outras gaitas, fui tocando, depois passei pra gaita pianada, né, essa que tu toca assim, onde eu tô até hoje. 40

Aos sete anos de idade vem a Porto Alegre, junto com a irmã, também deficiente visual, para aprender a ler e a escrever em braile, no internato do Instituto Santa Luzia. Lá fica até os 14 anos. Em 1965, volta com a irmã para Caçador, e ficam lá até 1973.

Durante este período, possuíam um programa de rádio em sua cidade natal, a "Revista Dominical":

Então, enquanto a firma patrocinou o programa, nós ficamos lá. Então, lá a gente cantou em conjunto, cantava em casamentos... Depois, quando a gente começou a sentir que não tava mais... que a firma parou de patrocinar, então a gente veio pra cá.

Isto foi em 1973, após ele e a irmã receberem uma carta da Irmã Diretora do Instituto Santa Luzia na época, convidando-os a voltar a Porto Alegre, a fim de trabalharem no Instituto.

40 Trecho de entrevista realizada em 31/01/2003, na sede da ACERGS. Todos os trechos citados neste capítulo foram retirados desta entrevista, conforme dito, única conversa com Josoel que pôde ser gravada, devido às dificuldades de gravação na movimentada "Rua da Praia", no centro da cidade, seu local de trabalho. 
Então, em 1974, de volta a Porto Alegre, Josoel passa a trabalhar no setor de controle de propagandas do Instituto Santa Luzia, um "serviço de escuta". Este serviço, segundo Josoel, consistia em "escutar se as propagandas estavam rodando bem, como as pessoas pediam pra rodar. (...) As propagandas que saíam da emissora eu anotava em braile e daí do braile era passado pra letra de vocês." Também em 1974 ele e a irmã associam-se na ACERGS. Josoel desenvolve este trabalho de escuta de 1974 a 1981, quando fecha este setor do Instituto. Vai trabalhar, então, numa firma que pertencia a um deficiente visual que funcionava na Galeria do Rosário, realizando o mesmo trabalho. Esta firma também fecha e, em 1984, passa a vender bilhetes lotéricos (loto) no centro de Porto Alegre:

\begin{abstract}
Eu vendi loteria 12 anos, sabe? Daí, como as vendas começaram a cair, né, eu comecei a ... ter problemas de nervos também, sabe? Porque... as vendas tavam muito ruins, eu tinha que sustentar uma família, né? A gente era muito enganado com dinheiro, davam dinheiro errado pra gente, sabe? Então aquilo foi me estressando, né? Aí eu procurei um psiquiatra. Aí ele disse "Olha, meu senhor, eu só tenho um conselho a te dar: tu deve voltar pra tua identidade." - "E qual é a minha identidade?" - "Música!". u comecei, com a minha esposa, a tocar na rua. Isso em... 1996. Em agosto, dia 4 de agosto de 96. Começamos a tocar no brique. Ali começamos a ... a nos dá bem, no brique, sabe? Aí, eu disse "Tu qué sabê de uma coisa... Então loteria agora a gente vai... vai deixar de lado". E a loteria caiu... mais!... Estrondosamente a queda da loteria, sabe? Não se vende mais loto, não se vende mais sena, não se vende mais megasena... Como se vendia antes, não. E daí, então... Que que eu fiz? Apelei pra música, começamos a tocá, começamos a tocar na rua...
\end{abstract}

Esta fala de Josoel pode ser analisada à luz do conceito de "projeto" desenvolvido por Velho (1987), caracterizado por um processo de verbalização: “é a verbalização, através de um discurso, que pode fornecer as indicações mais precisas sobre projetos individuais". ${ }^{41}$ Esta "reflexão e explicação que o sujeito faz sobre sua ação e conduta" 42 , expressa na fala de Josoel, também revela que "o projeto não é um fenômeno puramente interno, subjetivo"43. Assim, variáveis relacionadas às oscilações do mercado ambulante e, em última análise, à sobrevivência, certamente influenciam os projetos de Josoel. Por outro lado, apesar da noção de riscos e perdas, Josoel resolve não mais separarse da música, considerada por ele, nas palavras do psiquiatra, como a sua "identidade".

\footnotetext{
41 VELHO, Gilberto. Individualismo e Cultura: Notas para uma Antropologia da Sociedade Contemporânea. $4^{\mathrm{a}}$ ed. Rio de Janeiro: Jorge Zahar Editor, 1987, p.27.

42 Idem.

43 Idem.
} 
A música é identificada como uma questão central na vida de Josoel. Sem ela, ele perde sua identidade, "sofre dos nervos"44. Quando se trabalha com uma sociologia dos projetos, está se trabalhando com questões pessoais centrais. "Assim, uma sociologia dos projetos tem de ser, em alguma medida, sociologia das emoções." ${ }^{\prime 4}$ Foi com esta motivação que busquei nortear este estudo de história de vida.

\section{Considerações finais}

É impossível, para o pesquisador em campo, não se defrontar com tensões e questionamentos éticos no decorrer de sua pesquisa. No meu caso, já na primeira etapa, durante minhas caminhadas pela cidade, minha principal tensão em campo referiu-se a questões inerentes ao estudo de sociedades complexas, que comportam grupos, por um lado, diferentes (que demandam uma tentativa de familiarização com o estranho) mas por outro, com alguns costumes, língua, etc. comuns ao pesquisador (o que também demanda o esforço inverso de estranhamento do familiar).

A leitura de Caldeira (1988), Diniz (2001), Leal e Dos Anjos (1999) ajudaram-me a melhor lidar com elas. Conforme apontado por Caldeira, “o antropólogo não defronta mais membros de culturas isoladas ou semi-isoladas [mas, muitas vezes] membros de sua própria sociedade" ${ }^{\natural 6}$. Isto gera, para o pesquisador, necessidades novas, como o exercício já mencionado de familiarização com o estranho e exotização do familiar no interior de um mesmo grupo.

44 "Doença de nervos é uma expressão usada em camadas de renda mais baixa que cobre uma grande variedade e diferentes estados emocionais, sob o prisma de camadas médias intelectualizadas e 'psicologizadas'. Nesse universo, a pessoa pode estar deprimida, neurótica, rejeitada, obcecada, paranóica, descontrolada, instável, louca, com mania de perseguição, pirada, em crise, angustiada, etc. Isso não exclui que o mesmo universo que possa ter um vocabulário relativamente pobre quanto à descrição de estados emocionais possa, por outro lado, expressar-se verbalmente com muita riqueza em relação a outros temas como trabalho, sexualidade, esporte, samba, etc." (VELHO: 1987, p. 21, grifos do autor)

5 VELHO, Gillberto. Individuatismo e Cultura: Notas para uma Antropologia da Sociedade Contemporânea. $4^{a}$ ed. Rio de Janeiro: Jorge Zahar Editor, 1987, pp. 28, 29.

46 CALDEIRA, Teresa Pires do Rio. “A presença do autor e a pós-modernidade em Antropologia”. In: Novos Estudos do Cebrap. N. 21, julho 1988, p. 135. 
Estas são questões enfrentadas pela antropologia urbana que, sem a leitura de textos de pesquisadores especializados no tema (Gilberto Velho, Magnani, Cornelia Eckert e Ana Luiza Carvalho da Rocha) eu não conseguiria desenvolver. No estudo de sociedades complexas, talvez ainda mais que no de outros tipos de sociedades (se é que elas ainda existem em seu estado "puro"), o movimento de diálogo com o macro e a volta para o micro (histórias de vida, por exemplo) é, certamente, um desafio.

Estas questões, entretanto, só podem ser efetivamente resolvidas no momento da aproximação mesma como o grupo a ser estudado, através da troca de experiências cotidianas. A explicitação da relação em campo como dialógica foi uma escolha que fiz para a apresentação deste texto, na tentativa de não explicar fenômenos (até porque o convívio com o grupo foi breve para isto), mas demonstrar a situação de interação entre pesquisador e grupo pesquisado, primeira etapa da experiência etnográfica.

Assim, com cinco meses de pesquisa e as limitações de interação com o grupo daí decorrentes, fiz o possível. Espero que este "possível”, de alguma forma, possa ser útil para os deficientes visuais ambulantes do centro de Porto Alegre.

\section{Referencias}

BECKER, Howard. "Problemas de Inferência e Prova na Observação Participante". In: Métodos de Pesquisa em Ciências Sociais. Editora Hucitec.

BECKER, Howard. "Evidências de Trabalho de Campo". In: Métodos de Pesquisa em Ciências Sociais. Editora Hucitec.

BENJAMIN, Walter. "Pequena história da fotografia". In: KOTHE, Flávio R. (Org.). Walter Benjamin. $2^{a}$ ed. São Paulo: Ática S. A., 1991. 256 p.

BOURDIEU, Pierre et alli. A profissão do sociólogo, preliminares epistemológicas. Petrópolis: Vozes, 2002.

BRUMER, Anita (Coord.). Caminhos e Descaminhos da Cidadania: perspectivas da inclusão social, econômica, cultural e política dos portadores de deficiência visual em Porto Alegre. Porto Alegre, 2002.

CALDEIRA, Teresa Pires do Rio. "A presença do autor e a pós-modernidade em Antropologia”. In: Novos Estudos do Cebrap. N. 21, julho 1988.

CERTEAU, Michel de. A Invenção do Cotidiano. $3^{\mathrm{a}}$ ed. Petrópolis: Vozes, 1998. 351 p. COLLIER, J. Jr.. Antropologia Visual: a fotografia como método de pesquisa. São Paulo: USP, EPV, 1973.

DINIZ, Débora. "Antropologia e os limites dos Direitos Humanos: o dilema moral de Tashi". 
In. NOVAES, Regina; LIMA, Roberto Kant de. Antropologia e Direitos Humanos. Niterói, UFF, 2001.

ECKERT, Cornelia; ROCHA, Ana Luiza Carvalho da. Etnografia de Rua: Um Estudo de Antropologia Urbana.

GEERTZ, Clifford. A Interpretação das Culturas. Rio de Janeiro: Livros Técnicos e Científicos Editora S.A., 1989. 321 p.

GEERTZ, Clifford. O Saber Local - novos ensaios em antropologia interpretativa. Petrópolis: Vozes, 1997. 356 p.

GOFFMAN, Erving. Estigma - Notas sobre a Manipulação da Identidade Deteriorada. $4^{\mathrm{a}} \mathrm{ed}$. Rio de Janeiro: Guanabara, 1988.

GOMES, Celson Henrique Souza. Formação e Atuação de Músicos das Ruas de Porto Alegre: Um estudo a partir de relatos de vida. Dissertação (Mestrado em Música). Instituto de Artes, Universidade Federal do Rio Grande do Sul, Porto Alegre.

LEAL, Ondina e DOS ANJOS, José Carlos Gomes. Cidadania de quem? Possibilidades e Limites da Antropologia. In: Revista Horizontes Antropológicos $n^{\circ}$ 10: Diversidade Cultural e Cidadania, Porto Alegre, EDUFRGS, 1999.

MAGNANI, José Guilherme Cantor. "Quando o Campo é a Cidade: Fazendo Antropologia na Metrópole". In: Na Metrópole: textos de antropologia urbana. São Paulo: Editora USP, 1996.

MAGNI, Cláudia Turra. O Comércio Ambulante da Sorte. Porto Alegre, 1991, mimeo.

MALINOWSKI, Bronislaw. Um diário de campo no sentido estrito do termo. São Paulo, Editora Record.

OLIVEN, Ruben George. A Antropologia de Grupos Urbanos. Petrópolis: Vozes, 1985. 53 p. QUEIROZ, Maria Isaura. "Relatos orais: do indizível ao dizível". In: VON SIMSON, Olga de Moraes (Org.). Experimentos com Histórias de Vida (Itália - Brasil). São Paulo: Vértice, 1988.

REVISTA HORIZONTES ANTROPOLÓGICOS. Porto Alegre: UFRGS, PPGAS, n. 12, 1999. Título do fascículo: Cultura Oral e Narrativas.

RILLO, Sandro Belloli. A Cidade e os seus riscos: o viver de deficientes visuais em Porto Alegre. Porto Alegre, 2001.

SALEM, Tânia. "Roteiro de entrevista". In: ___. Um estudo de papéis e conflitos familiares. Petrópolis, Vozes, 1980.

VELHO, Gilberto. Individualismo e Cultura: Notas para uma Antropologia da Sociedade Contemporânea. $4^{\text {a }}$ ed. Rio de Janeiro: Jorge Zahar Editor, 1987. 149 p.

VELHO, Gilberto. Projeto e Metamorfose. Antropologia das Sociedades Complexas. Rio de Janeiro: Zahar, 1994.

VELHO, Gilberto. A Utopia Urbana: Um Estudo de Antropologia Social. Rio de Janeiro: Zahar, 1989.

WINKIN, Yves. A nova comunicação. São Paulo: Papirus, 1998.

ZALUAR, Alba. Desvendando Máscaras Sociais. $2^{\text {a }}$ ed. Rio de Janeiro: Livraria Francisco Alves Editora S. A., 1980. 